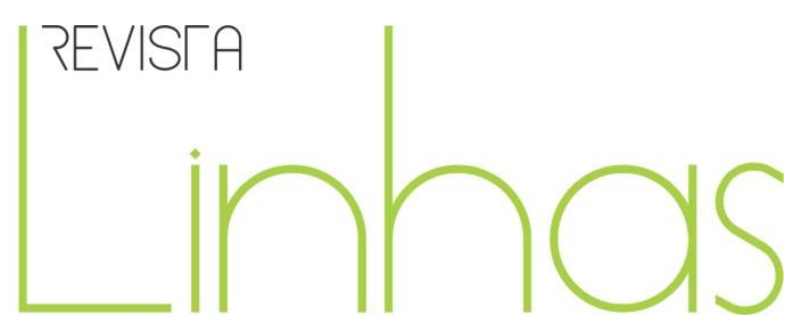

\title{
A reprodução da reprodução sociocultural: sem crítica, com culpa e com primazia da informação ${ }^{1}$
}

\begin{abstract}
Resumo
Esta pesquisa investiga em que medida a reprodução sociocultural, quando presente na formação inicial de professores, é transferida para a atuação na educação básica. A nova educação superior, sucessora da elitista, move-se no contexto da velha massificação, cabendo questionar se a sua expansão se sustenta na ideia de neutralidade da escola. Como antes, continua o debate sobre a educação que contribui para emancipar ou alienar. A herança vinculada à origem social dos estudantes ainda explica as trajetórias escolares e as diferenças de capital cultural. Assim, buscou-se identificar tendências à mencionada reprodução. Esta pesquisa descritivo-explicativa, com um estudo de casos múltiplos envolvendo duas licenciaturas, confirmou a hipótese de que em cursos de formação de professores há tendências à inércia do processo educacional, negação parcial dos sujeitos e autoritarismo.
\end{abstract}

Palavras-chave: Educação Superior. Educação Básica. Reprodução Sociocultural. Formação de Professores.

\author{
Ivar César Oliveira de \\ Vasconcelos \\ Universidade Paulista - UNIP - \\ Brasil \\ ivcov@hotmail.com
Candido Alberto da Costa Gomes Universidade Católica de Brasília - UCB - Brasil clgomes@terra.com.br

\begin{abstract}
Para citar este artigo:
VASCONCELOS, Ivar César Oliveira de; GOMES, Candido Alberto da Costa A reprodução da reprodução sociocultural: sem crítica, com culpa e com primazia da informação. Revista Linhas. Florianópolis, v. 18, n. 37, p. 210-238, maio/ago. 2017.
\end{abstract}

\section{DOI: $10.5965 / 1984723818372017210$}

http://dx.doi.org/10.5965/1984723818372017210

\footnotetext{
${ }^{1}$ Este trabalho foi parcialmente possível graças ao apoio da Coordenação de Aperfeiçoamento de Pessoal de Nível Superior (CAPES), relativamente a uma bolsa de estudo ao primeiro autor no âmbito do Programa Nacional de Pós-Doutorado (PNPD), conforme Edital da Universidade Católica de Brasília (UCB) Nº 01/2015.
} 


\section{Reproduction of sociocultural reproduction: without criticism, with guilt and with predominance of information}

This paper aims to investigate the extent in which the sociocultural reproduction, when part of the teachers training, is transferred to their work in fundamental education. The recent college education, successor of the former elitist model, evolves in a context of old massification and that is why it is worth asking if it sustains itself on a perspective of school neutrality. Like before, the debate on the education that contributes for emancipation or for alienation continues. The heritage linked to the social background of the students still explains their trajectories in school and the differences in cultural capital. Therefore, we seek to identify tendencies to the mentioned reproduction. This descriptiveexplanatory research, with a multiple case study involving two teacher education programs, confirmed the hypothesis that in teacher training programs there are tendencies to inertia of the educational process, to partial denial of the individuals and to authoritarianism.

Keywords: Higher Education. Basic Education. Sociocultural Reproduction. Teacher Education. 


\section{Introdução}

Caracterizada pela inserção de estudantes de classes populares antes excluídas, a explosão da educação superior levou à diferenciação crescente dos estabelecimentos, apesar da unificação formal e da inflação dos diplomas. Nesse contexto, a dinâmica curricular frequentemente pouco favorece o exercício do protagonismo pelos jovens. Os professores se ressentem do desinteresse de parte dos estudantes, levando à impaciência na sala de aula. Sentem-se descontentes com o monólogo expositivo, preocupando-se com a insuficiência de leitura, em geral, reduzida aos temas dos planos de ensino. Percebem que a pouca atividade de pesquisa interfere na sua capacidade de autocrítica, inclusive sobre os modos de ensinar. Assim, como num enxame, escola, estudantes e professores ziguezagueiam numa profusão de comunicados, encontros e desencontros, fazendo parte de um tempo em que as relações sociais são cada vez mais pulverizadas.

Portanto, tal contexto se insere noutro mais abrangente. Mergulhados na complexa teia em que se tornou o mundo, dissolvido na modernidade líquida (BAUMAN, 2001), os indivíduos se orientam e vivenciam relações sociais produzidas e explicadas menos conforme lógicas de ação razoavelmente organizadas e mais de acordo com a autonomia construída na pluralidade de valores e na constante ruptura. O mundo "duro" cede lugar ao "suave" (SERRES, 2013). No primeiro predomina a ideia de eficácia sobre as coisas. No segundo, sobre as instituições humanas.

Precisamente nesse mundo "suave", em liquefação, as relações sociais podem ser evidenciadas e explicadas não mais a partir da clássica ideia de ação, podendo ser definidas pela noção de "experiência social". O termo designa condutas (atitudes e comportamentos), individuais ou coletivas, construídas na pluralidade de princípios e na ação dos indivíduos, os quais se obrigam cada vez mais a encontrar sentido no que realizam (DUBET, 1994). Compatibiliza, portanto, com a ideia de sujeito pós-moderno, com identidade não mais integrada, única, como informava a explicação iluminista, mas identidade contraditória, impelida por sociedades plurais para diferentes direções.

Nesse cenário, os indivíduos se desenvolvem também no âmbito da educação formal. No nível da educação superior, a diversidade de públicos acompanha a intensa 
expansão ocorrida nas últimas décadas. Verificam-se impactos desde os sistemas educacionais até a atuação docente na sala de aula. Diante de tal expansão em escala mundial, as instituições vinculadas a esse nível de ensino passaram a acolher populações de diversificadas origens socioculturais, com influência, por exemplo, em políticas educacionais, currículos e práticas didático-pedagógicas, embora tenha permanecido a ideia de neutralidade da escola assente no ideal modernista, com ímpeto de tudo planificar.

Desse modo, revigoram-se as discussões a respeito da educação favorável à emancipação de estudantes e professores. A herança vinculada à origem social dos estudantes continua a explicar as variações nos percursos escolares e as diferenças de capital cultural. Na universidade o risco de reproduzir, sem transformar, se torna muito presente. Há seleção do tipo de cultura a ser internalizada pelos alunos, priorizando padrões culturais médios (SANTOS, 2005), priorizando a formação para o trabalho e, por consequência, indicando o credenciamento de competências. Ao selecionar, impõe um arbitrário cultural (BOURDIEU; PASSERON, 1964) que, por sua vez, se constitui em caminhos por onde passará a atuação didático-pedagógica. Aspectos dessa reprodução foram identificados em trabalho sobre a interação das experiências sociais de jovens estudantes e professores universitários (ou meramente interação social) (VASCONCELOS; GOMES, 2015). Ficou sinalizado que tal reprodução se reproduz na atuação de egressos dos cursos de licenciatura. Verificou-se que há mútua culpabilização por insucessos do processo educacional, envolvendo estudantes, professores e a instituição escolar e, assim, contribuindo para gerar um cenário de paralisação do sistema educacional. Há crítica silenciosa, elaborada por estudantes e professores, colocando às escuras a fala e a ação de uns e outros, sendo responsável pela tendência à negação parcial dos sujeitos, pois os impede de manifestar opiniões sobre vivências no dia a dia da instituição. Há primazia da informação, que não se articula com a formação, levando ao autoritarismo no processo educacional - os que mais conhecem podem impor interesses alheios aos da coletividade.

A mencionada articulação é compreendida como a ação educativa que aproxima conhecimentos teórico-práticos e desenvolvimento humano e, desse modo, caracterizase pela maior amplitude em relação aos conhecimentos. O pano de fundo é a integração 
entre saber e consciência concretizada com o uso de princípios que organizam os saberes, favorecendo a emergência de sentidos e o desenvolvimento de competências para identificar e lidar com problemas.

No entanto, já se observou que, na verdade, a informação tem sido o astro-rei da sala de aula, sendo o patamar epistemológico e ontológico sobre o qual têm se desenvolvido as interações de estudantes e professores, como nos casos em que se culpam e se negam mutuamente. Já foram identificados discursos como: "O aluno vive dando rasteira no professor; acho mesmo que eles são preguiçosos..." (dito por docente da educação superior); “durante o curso, a universidade vai te empurrando igual a um lixo; o sexto ano é a lixeira" (dito por discente do curso de Pedagogia, quinto semestre, numa alusão aos processos industriais adotados pela universidade).

Parece existir um círculo vicioso em que, mergulhados na preocupação em dominar informações, estudantes de licenciatura e seus professores tendem a culpar-se mutuamente e a desconsiderar a capacidade crítica deles próprios e, assim, terminam por fertilizar o solo onde germina a reprodução sociocultural - compreendida como reprodução da estrutura das relações de força entre classes sociais, a qual tende a se prolongar por meio da atuação do professor quando este promove a distribuição desigual do capital cultural dos diversos grupos humanos com os quais convive (BOURDIEU; PASSERON, 1992). Para os professores que lidam há tempos com a educação formal nos diversos níveis de ensino, as idas e voltas da dinâmica dessa reprodução se assemelham às tempestades de Júpiter, maiores do que o planeta Terra e que têm durado centenas de anos. Por quanto tempo ainda durará tal reprodução sociocultural?

Diante disso, buscou-se verificar em que medida ocorre transferência dessa reprodução, da universidade para a escola, por meio da atuação de professores. Desde a teoria das desigualdades, em Rousseau ([1755] 1997), sabe-se que estas tendem a acumular-se. Com efeito, indivíduos que advêm de famílias modestas, em geral, não obtêm um nível alto de instrução (BOUDON; BOURRICAUD, 1993), havendo nisto desencontros de percepções, orientações e relacionamentos.

Assim, renovando as discussões a respeito da educação que emancipa ou aliena, este trabalho se encaminhou, por um lado, para as teorizações sobre o possível papel reprodutor da escola, detendo-se sobre práticas escolares. Por outro lado, considerou as 
interações sociais de estudantes e professores como o âmbito possível de identificar meios de romper a reprodução de desigualdades socioculturais, tantas vezes consolidadas de professor para professor ao longo da vida estudantil². Desse modo, expresso em termos de "reprodução que reproduz", o tema da pesquisa desenvolveu-se a partir das questões: durante a formação inicial de professores, estudantes e seus formadores mantêm atitudes e comportamentos que caracterizam mútua culpabilização pelos insucessos do processo educacional? Caracterizam a presença da crítica silenciosa de uns e de outros? Caracterizam a primazia da informação, portanto, desarticulada dos aspectos formativos da educação? Caso existam, esses aspectos contribuem para estabelecer a reprodução sociocultural na sala de aula? Quais processos se evidenciam como transferência dessa reprodução para a sala de aula da escola básica? De modo sintético, em que medida a reprodução sociocultural, quando presente na atuação de professores universitários, é transferida para a atuação de professores da educação básica?

Entretanto, por que realizar este estudo? Mesmo as argumentações de que a qualidade da formação básica é fator decisivo em relação aos sistemas de educação superior (DUBET, 2015), não se pode esquecer que os professores que nesta atuarão têm formação inicial na universidade. Em consonância com isso, educar, conforme a Lei de Diretrizes e Bases da Educação Nacional, é tarefa abrangente, envolvendo processos formativos implicados na vida da família, na convivência entre os seres humanos, nos contextos de trabalho, nas instituições de ensino e pesquisa, além dos que ocorrem em movimentos sociais e organizações da sociedade civil e manifestações culturais (BRASIL, 1996). Desse modo, constitui-se em fator de desenvolvimento de um povo, a exemplo da cidadania, fundamento do modelo democrático de convivência entre os membros de uma comunidade. No caso do Brasil, país de contrastes, falar em educação significa, sobretudo, falar em esperança de solução para enormes e complexos desafios. Esperança de mudar realidades desfavoráveis arquitetadas e cultuadas há séculos.

A melhor compreensão do assunto pode contribuir para barrar o fluxo de aspectos, efetivos potenciais de um círculo vicioso de reprodução sociocultural presente

\footnotetext{
${ }^{2}$ A maior força sobre o comportamento dos estudantes é o "exemplo de ex-professores, [sendo] este dado fundamental para quem trabalha na educação de professores, pois identifica o ciclo de reprodução que se realiza nas relações escolares" (CUNHA, 1989, p. 160).
} 
na formação inicial de professores que prossegue na atuação destes na educação básica. Consequentemente, pode contribuir para promover a transformação social.

\section{Estrutura reprodutiva na sala de aula}

A reprodução cultural é o processo social perpassado por manifestações culturais em modos análogos aos existentes. Sendo assim, conta com o apoio de instituições, dentre elas a escola. Com efeito, a reprodução cultural participa de dinâmica mais ampliada de reprodução social que, em determinados âmbitos, pode arrastar sociedades inteiras em suas características culturais, estruturais, ecológicas e assim por diante. Desse modo, a reprodução sociocultural é a "reprodução da estrutura das relações de força entre as classes" (BOURDIEU; PASSERON, 1992, p. 25). Na escola, a atuação do professor tende a imitar a estrutura que define a distribuição do capital cultural entre os grupos ou classes, o que leva igualmente a imitar a mesma estrutura social.

É o caso da escola "linha de montagem". Como uma espécie de herança do ocorrido durante a passagem do trabalho artesanal para o fabril, as escolas construídas sob tal modelo tendem a passar conhecimentos e habilidades que, na verdade, são pensados "de fora" para "dentro". Assim, tornaram-se "fábricas" de seres humanos, cada indivíduo tomado inicialmente como unidade sobre a qual se depositam informações, dados, conhecimentos, efetivamente advindos de uma cultura já construída em processos sociais mais amplos (SAVIANI, 2008). Diante disso, refletiu-se: quais elementos estariam a compor a estrutura reprodutiva na sala de aula da universidade ou da escola da educação básica? Como se vinculam condutas individuais, decorrentes do uso de lógicas de ação, e configurações sociais que, por sua vez, definem o desenho do processo educacional?

Ao se propor pensar a respeito de tal estrutura, este estudo situou a reprodução sociocultural, espacialmente na sala de aula dos cursos de licenciatura, projetando-a para a sala de aula da educação básica e, teoricamente, num circuito de relações sociais integradas. Evidenciou-se que ela se delineia por certas tendências, entre as quais a inércia do sistema educacional, a negação parcial dos sujeitos e o autoritarismo, 
fundamentados, respectivamente, em três lógicas de ação: mútua culpabilização, crítica silenciosa e primazia da informação (ver Fig.1).

Figura 1 - Estrutura reprodutiva na sala de aula.

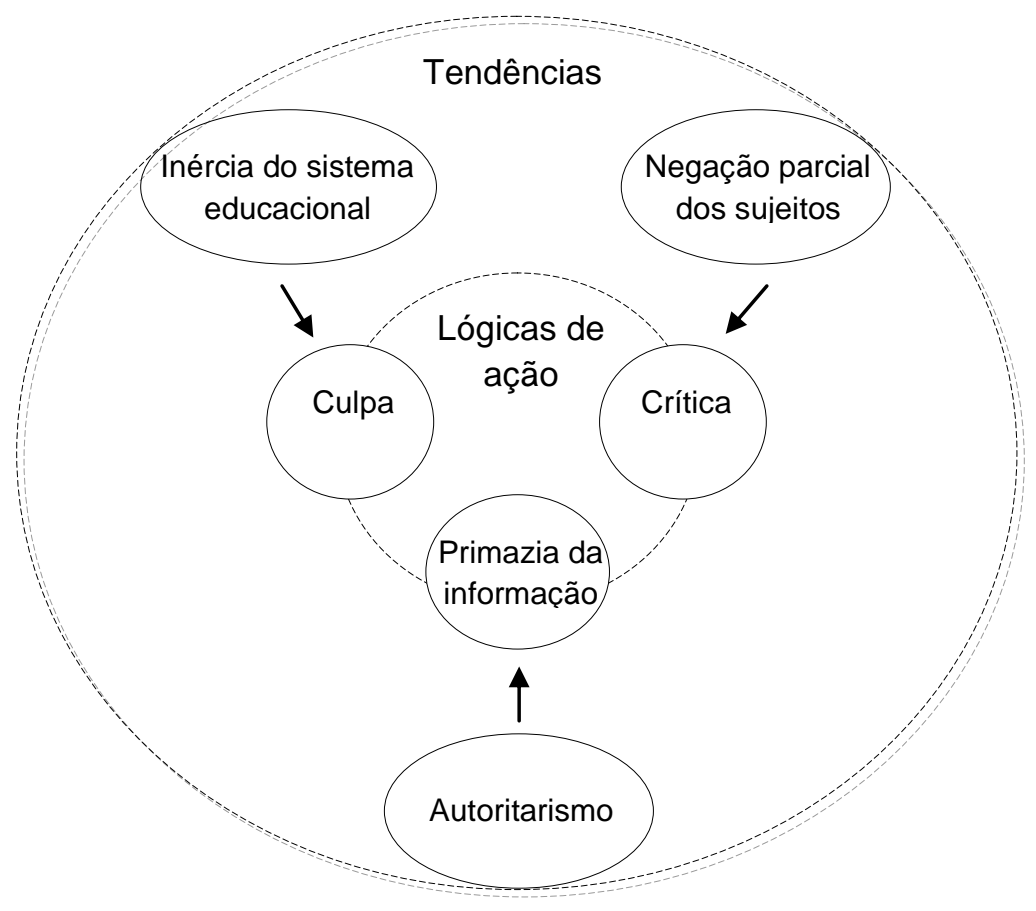

Fonte: elaboração dos autores, com base em Vasconcelos e Gomes (2015).

Essas tendências e seus fundamentos foram identificados em pesquisa realizada com estudantes e professores universitários (VASCONCELOS; GOMES, 2015). Com as evidências empíricas, estabelecera-se o paralelismo entre teoria-empiria-teoria, tendo como base os conceitos de experiência social (DUBET, 1994) e pedagogia dialógica (FREIRE, 2011) (ver Quadro 1). 
Quadro 1 - Tendências e lógicas de ação: a base teórica.

\begin{tabular}{|c|c|c|}
\hline $\begin{array}{l}\text { Teoria: experiência } \\
\text { social }\end{array}$ & $\begin{array}{c}\text { Empiria: lógicas de ação } \\
\text { e tendências }\end{array}$ & $\begin{array}{l}\text { Teoria: pedagogia } \\
\text { dialógica }\end{array}$ \\
\hline $\begin{array}{l}\text { Condutas } \\
\text { perpassadas pela } \\
\text { heterogeneidade de } \\
\text { princípios. }\end{array}$ & $\begin{array}{l}\text { A lógica da atribuição de culpa ao } \\
\text { outro. Eventuais insucessos do } \\
\text { processo educacional advêm da ação } \\
\text { do Outro. Na sequência, leva à inércia } \\
\text { do sistema educacional. } \\
\\
\text { O que fazer: aproveitar potenciais } \\
\text { identificados pela pesquisa (neste e } \\
\text { nos demais casos a seguir). }\end{array}$ & $\begin{array}{l}\text { "Eu-Isso", termo } \\
\text { representativo das } \\
\text { relações de cada ser } \\
\text { humano com o } \\
\text { mundo, com os } \\
\text { sistemas de relações } \\
\text { sociais. }\end{array}$ \\
\hline $\begin{array}{l}\text { Distanciamento do } \\
\text { indivíduo com relação } \\
\text { ao sistema } \\
\text { sociocultural. }\end{array}$ & $\begin{array}{l}\text { A logica da crítica silenciosa. A } \\
\text { manifestação de opiniões não se } \\
\text { completa. Nega-se a criticidade de } \\
\text { estudantes e professores. Portanto, } \\
\text { estes se negam parcialmente como } \\
\text { seres humanos. }\end{array}$ & $\begin{array}{l}\text { “Eu”, representativo } \\
\text { do ser capaz de } \\
\text { posicionar-se por } \\
\text { intermédio de críticas } \\
\text { cognitiva e/ou } \\
\text { normativa. }\end{array}$ \\
\hline $\begin{array}{l}\text { Dominação social } \\
\text { ocorre na dispersão e } \\
\text { não na unificação da } \\
\text { experiência coletiva. }\end{array}$ & $\begin{array}{l}\text { A lógica da primazia da informação. } \\
\text { Pouca articulação entre informar- } \\
\text { formar. Isso favorece o autoritarismo, } \\
\text { traduzido na frase "manda quem tem } \\
\text { mais informação". }\end{array}$ & $\begin{array}{l}\text { "Eu-Tu", } \\
\text { representativo das } \\
\text { relações } \\
\text { interindividuais, } \\
\text { sendo de logos para } \\
\text { logos. }\end{array}$ \\
\hline
\end{tabular}

Fonte: elaboração dos autores, com base em Vasconcelos e Gomes (2015).

\section{A pedagogia reprodutora}

Os estudos das tendências e seus fundamentos conduziram para perguntas em torno do conceito de ação pedagógica. Esta pode ser compreendida como um exercício de violência simbólica ao reproduzir indefinidamente a seleção arbitrária de um grupo ou classe que opera enquanto se estabelece o arbitrário cultural. Como reproduziria? Meramente impondo e inculcando certas significações selecionadas "previamente", ou moldadas pela exclusão do que não interessa a quem domina! Reproduz-se a cultura dominante, incluindo a reprodução das relações de poder de determinado grupo social, dissimuladas sob a forma de relações simbólicas. É de fato a adaptação recíproca de "informações" aos indivíduos. Desse modo, constituindo uma pedagogia reprodutora, o 
eixo da atuação do professor se baseia na seleção de determinadas significações que ao cabo passam a definir a cultura de um grupo ou de uma classe como sistema simbólico (BOURDIEU; PASSERON, 1992).

Assim, para este trabalho, o que se estudou a respeito das tendências e seus fundamentos, na vinculação com o conceito de ação pedagógica no escopo da teoria reprodutivista, levou a montar uma figura representativa da pedagogia reprodutora (ver Fig. 2).

Figura 2 - Pedagogia reprodutora: algumas tendências e lógicas de ação.

\section{Pedagogia reprodutora}

Sem encontro, diálogo e possibilidades de mudança.

Estudantes e professores em espaços diferentes. Sem novos conhecimentos.

Separação dos diversos tipos de conteúdos.

Fonte: elaboração dos autores. 
Em primeiro lugar, compreende-se que a seleção de significações aptas a constituir a pedagogia reprodutora inclui aspectos importantes da tendência à inércia do sistema de ensino baseada na mútua culpabilização pelos insucessos do processo educacional. Segue-se a ideia de "seleção", caracterizada como arbitrária na medida em que esta não passa pelo filtro do raciocínio dedutivo, o que, caso ocorresse, faria com que funções da cultura envolvida fossem extraídas de princípios mais ou menos universais, que, por serem universais, isentam-se da conexão interna com uma possível natureza humana (BOURDIEU; PASSERON, 1992). Ora, o que é a mencionada culpabilização senão a tentativa de excluir o Outro do usufruto de princípios mais ou menos universais (dialogar, sonhar, agir)?

Aquele que culpa o outro pelo que ocorre de inesperado à sua volta, fundamentalmente, nega a capacidade de dialogar, superar obstáculos, abrir possibilidades. Portanto, abandona o pressuposto de princípios universais. Na verdade, o indivíduo que assim se conduz age por precipitação, com ações impensadas. Identifica o outro, entretanto, imediatamente o exclui de qualquer possibilidade de ação. Em seguida, ao propor a culpa do outro pelos insucessos do processo educacional, esse mesmo indivíduo ajuda, por exemplo, a paralisar o sistema porque retira a ação humana do jogo em que se buscam soluções, sem calcular (sentido weberiano), sem considerar valores importantes do grupo social. Essa atitude de culpabilização ajuda a manter determinadas significações que não entram na pauta de diálogos, pois estes sequer existiriam no horizonte de estudantes e professores. De tal modo que a própria tendência à inércia contribui para definir a cultura que molda e alimenta a reprodução sociocultural.

Em suma, constrói-se a pedagogia reprodutora na ação do educador com dificuldades de promover efetivo encontro com os estudantes, o que, caso ocorresse, proporcionaria diálogos importantes e, assim, abrir-se-iam possibilidades de mudanças do processo educacional em prol de sua maior humanização.

Em segundo lugar, admite-se que a seleção de significações inclui aspectos da tendência à negação parcial dos sujeitos, às voltas com o não reconhecimento de sua capacidade crítica. Se a ação pedagógica pode se constituir no trabalho da escola, disseminando-se pelos quatro cantos da instituição escolar, os membros desta deixam de 
perceber a dependência de suas ações à configuração social do contexto onde se inserem.

Ora, negar a criticidade dos que constroem a escola é alimentar essa ausência de percepção. Não reconhecer a capacidade crítica, o que nega em parte os sujeitos, leva a que os implicados não percebam que a escola, pela força de sua institucionalidade, produz e reproduz as condições que a tornam reprodutora da cultura. Desse modo, negar parcialmente os sujeitos é garantir a pretensa neutralidade da escola, que reproduz o arbitrário cultural que, por sua vez, solidifica a reprodução sociocultural. Permanece camuflada a verdadeira feição da ação pedagógica reprodutora, submissa ao sistema de ensino dominante.

Tal seleção se desenvolve no contexto das relações de comunicação. Esta não ocorre efetivamente entre quem exerce a ação pedagógica e quem a recebe (BOURDIEU; PASSERON, 1992), pois essa ação não se revelará como violência simbólica. A linguagem utilizada por qualquer professor na sala de aula segue já carregada de símbolos. Falar destes já implica embutir o que há de simbólico, caracterizando um paradoxo ao qual o professor fica continuamente preso. Assim, a crítica permanece fora. Não há efetiva comunicação na ação pedagógica reprodutora.

Constata-se, então, que os contornos da negação parcial dos sujeitos, nos termos deste trabalho, delineiam-se também pela comunicação pedagógica, algo definível para além da mera relação de comunicação. Há um tipo de exclusão, uma negação parcial, que chega ao limite do humano, evidenciando a necessidade de reaprender a se comunicar. É necessário estabelecer uma pedagogia da inclusão humana.

Em síntese, a ação pedagógica reprodutora se constitui também na dificuldade do educador de situar-se no mesmo espaço ontológico, epistemológico e pedagógico do estudante. Nisto se desperdiçam oportunidades de exercitar a abertura ao mundo e aos outros. Não se estabelece comunicação favorável à ampliação de conhecimentos, pois o sabido é petrificado.

Nesse sentido, em terceiro e último lugar, interpreta-se que a seleção de significações realizada pela ação pedagógica reprodutora inclui aspectos da tendência ao autoritarismo decorrente da primazia do uso de informações durante a operacionalização 
do processo educativo. As significações tidas como legítimas se caracterizam como poder de violência simbólica. Isso porque tal poder, segundo os formuladores do conceito, realimenta-se da própria força simbólica, fortalecendo as relações de força.

Ora, o que é o autoritarismo decorrente do uso de informações, em vez da articulação com os aspectos formativos da educação? É justamente o uso da informação, em dado contexto, para impingir falsa autoridade. Na sala de aula, sem ter de imediato a visão de contexto favorável ao seu desenvolvimento integral - o indivíduo pensa, emociona-se, age -, o estudante fica refém da ação coercitiva do professor. Este the passa a ideia de importância definitiva da informação transmitida. Assim, concorre para a permanência da vinculação entre autoritarismo e violência simbólica - aquele garantindo a legitimidade desta. Assim, resta a reprodução sociocultural.

Ao interagir com seus alunos, o professor pode encontrar apoio à sua autoridade numa linguagem restrita a termos padronizados, impactando a geração de novos conhecimentos. Na universidade, o emprego seguro do idioma universitário por professores não é por acaso. Igualmente, não é por acaso que existe tolerância dos estudantes à ignorância semântica. Está tudo, ou quase tudo, institucionalizado.

Desse modo, também se constitui em amálgama da pedagogia reprodutora os momentos em que o educador focaliza, quase exclusivamente, os conceitos durante sua atuação, mantendo ao largo as atitudes e os esforços que possam contribuir para evidenciar aos educandos o que fazer com os conhecimentos construídos. É pedagogia reprodutora quando ele não consegue integrar os diversos saberes, valores e afetividades.

\section{Metodologia}

Esta pesquisa, descritivo-explicativa, tem natureza qualitativa, tendo sido um estudo de casos múltiplos. Analisaram-se os Projetos Pedagógicos de Curso e os Planos de Ensino. Entretanto, a coleta e a geração de dados se concentraram nas observações e entrevistas. Foram 10 horas de observações diretas ( 12 aulas vezes 50 minutos cada uma) e 10 horas de entrevistas semiestruturadas (cinco horas para estudantes e cinco para professores). 
Quadro 2 - Características dos casos únicos.

\begin{tabular}{|c|c|c|c|}
\hline \multicolumn{2}{|c|}{ Campo da pesquisa } & \multicolumn{2}{|c|}{ Unidades de análise (casos únicos) } \\
\hline \multirow{4}{*}{ 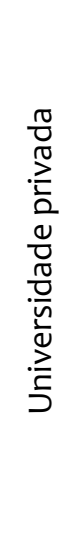 } & \multirow[t]{2}{*}{$\begin{array}{c}\text { Cursos de } \\
\text { licenciatura }\end{array}$} & \multicolumn{2}{|c|}{$\begin{array}{l}\text { Aspectos da atuação e percepção de estudantes e professores universitários } \\
\text { presentes nas lógicas da mútua culpabilização por insucessos do processo } \\
\text { educacional, da crítica silenciosa e da primazia da informação, capazes de } \\
\text { contribuir para reprodução sociocultural por meio desse processo na sala de aula } \\
\text { da universidade ou da escola da educação básica, constituindo elementos de } \\
\text { uma possível transferência da dita reprodução de uma para a outra destas } \\
\text { instituições. }\end{array}$} \\
\hline & & Número & Unidades de contexto \\
\hline & Pedagogia & 1 & Interações sociais entre $A_{1}, A_{2}, A_{3}, A_{4}, A_{5}, P_{1}, P_{2}$ e $P_{3}$. \\
\hline & Letras & 2 & Interações sociais entre $A 5, A 6, A 7, A 8, A 9, A 10, P_{4}, P_{5}$ e P6. \\
\hline
\end{tabular}

Fonte: elaboração dos autores. Legenda: A1, A2, A3, A4, A5, A6, A7, A8, A9 e A10 - Alunos. P1, P2, P3, P4, P5 e P6 - Professores.

Vê-se pelo Quadro 2 que a pesquisa foi realizada numa universidade privada de Brasília. A universidade é uma instituição que se propõe a educar a educação básica ao formar profissionais que nesta atuarão. A ela se aplica o Relatório Delors, apesar de este ser voltado para a educação básica. Ela enfatiza a contínua renovação dos conhecimentos. Portanto, se propõe a desenvolver os quatro pilares da educação para o século XXI (DELORS et al., 1998). Já os cursos escolhidos, com presença tipicamente feminina, foram licenciaturas em Pedagogia e Letras.

Participaram da pesquisa seis docentes (cinco mestres e uma doutora), tendo sido duas professoras e um professor em cada curso, e dez de seus alunos, sendo quatro mulheres e um homem em cada curso.

Tendo sido um estudo de casos múltiplos, as constatações são possibilidades no restrito universo considerado. Como tal, proporcionam reflexões e alternativas de solução para outros casos que envolvam processos educacionais desenvolvidos na sala de aula de cursos de formação inicial de professores. 


\section{A presença da culpa, crítica silenciosa e primazia da informação}

Com as análises, identificaram-se nas práticas docentes aspectos da mútua culpabilização, crítica silenciosa e primazia da informação, confirmando resultados da pesquisa antes realizada (VASCONCELOS; GOMES, 2015) (ver Quadro 3).

Quadro 3 - Mútua culpabilização, crítica silenciosa e primazia da informação

\begin{tabular}{|c|c|c|c|c|}
\hline & $\begin{array}{l}\text { Mútua } \\
\text { culpabilização: } \\
\text { quem é o } \\
\text { culpado? (a) }\end{array}$ & $\begin{array}{l}\text { Crítica } \\
\text { silenciosa: } \\
\text { existe ou } \\
\text { não? (b) }\end{array}$ & $\begin{array}{l}\text { Primazia da } \\
\text { informação: qual o } \\
\text { tipo de conteúdo } \\
\text { priorizado? } \\
\text { (c) }\end{array}$ & $\begin{array}{l}\text { Práticas docentes: } \\
\text { identificação de aspectos } \\
\text { relacionados com } \\
\text { (a), (b), (c) }\end{array}$ \\
\hline $\mathrm{A} 1$ & A el & $\mathrm{s}$ & Conceitos & \multirow{10}{*}{ Não se aplicou. } \\
\hline A2 & $A, P$ e I & $\mathrm{s}$ & $\begin{array}{c}\text { Conceitos, } \\
\text { procedimentos }\end{array}$ & \\
\hline$A_{3}$ & $\mathrm{I}$ & $\mathrm{S}$ & Conceitos & \\
\hline A4 & $\mathrm{A}, \mathrm{PeI}$ & $\mathrm{s}$ & Conceitos & \\
\hline A5 & 1 & $\mathrm{~s}$ & Conceitos & \\
\hline A6 & A & $\mathrm{s}$ & $\begin{array}{c}\text { Conceitos, atitudes, } \\
\text { procedimentos }\end{array}$ & \\
\hline A7 & A & $\mathrm{S}$ & Conceitos & \\
\hline A8 & A & $\mathrm{s}$ & $\begin{array}{c}\text { Conceitos, } \\
\text { procedimentos }\end{array}$ & \\
\hline A9 & A & $\mathrm{s}$ & $\begin{array}{c}\text { Conceitos, atitudes, } \\
\text { procedimentos }\end{array}$ & \\
\hline $\mathrm{A} 10$ & $A$ & $S$ & $\begin{array}{c}\text { Conceitos, } \\
\text { procedimentos }\end{array}$ & \\
\hline $\mathrm{P} 1$ & $P$ & $\mathrm{~N}$ & $\begin{array}{c}\text { Conceitos, } \\
\text { procedimentos }\end{array}$ & $\begin{array}{l}\text { Sem atribuiç̃ão de culpa. Sem } \\
\text { manifestação de críticas. Com } \\
\text { articulação de conteúdos }\end{array}$ \\
\hline $\mathrm{P} 2$ & A & $\mathrm{s}$ & Conceitos, atitudes & $\begin{array}{l}\text { Sem atribuição de culpa. Com } \\
\text { manifestação de críticas, com } \\
\text { abertura a estas. Com } \\
\text { articulação de conteúdos, } \\
\text { contudo, sem clareza disto } \\
\text { para os alunos. }\end{array}$ \\
\hline$P_{3}$ & I & $S$ & Conceitos & $\begin{array}{l}\text { Sem atribuição de culpa. Sem } \\
\text { manifestação de críticas. } \\
\text { Priorização para o repasse de } \\
\text { informações. }\end{array}$ \\
\hline P4 & A & $S$ & $\begin{array}{l}\text { Conceitos, atitudes, } \\
\text { procedimentos }\end{array}$ & $\begin{array}{l}\text { Sem atribuição de culpa. Com } \\
\text { manifestaçẫo de críticas. Com }\end{array}$ \\
\hline
\end{tabular}




\begin{tabular}{c|c|c|c|c}
\hline & & & & articulação de conteúdos. \\
\hline P5 & A & S & Conceitos & $\begin{array}{c}\text { Sem atribuição de culpa. Sem } \\
\text { manifestação de críticas. Com } \\
\text { articulação de conceitos e } \\
\text { atitudes (com perguntas). }\end{array}$ \\
\hline P6 & A & - & $\begin{array}{c}\text { Conceitos, atitudes, } \\
\text { procedimentos }\end{array}$ & $\begin{array}{c}\text { Sem atribuição de culpa. Sem } \\
\text { manifestação de críticas, com } \\
\text { abertura a estas. Com } \\
\text { articulação de conteúdos. }\end{array}$
\end{tabular}

Fonte: elaboração dos autores. Legenda: A - Aluno. P - Professor. I - Instituição. S - Sim. N - Não.

Tanto na universidade anteriormente pesquisada como na que se serviu como local para esta nova investigação, ficou visível a capacidade crítica dos alunos, apesar de manifestarem pouco suas opiniões no dia a dia. Estas são realizadas às sombras, entre eles, sem o hábito de criticar abertamente o processo educacional. No entanto, nesta pesquisa, ficou mais evidente a presença da autocrítica entre os alunos. Eles reconhecem que o sucesso ou insucesso do processo educacional depende deles também. E tal autocrítica ocorre na medida diretamente proporcional à maior articulação dos conteúdos conceituais, atitudinais e procedimentais pelos professores (COLL et al., 1998), conforme consta do Quadro 3.

No curso de Pedagogia, no qual se verificou a primazia da informação sobre aspectos formativos, os estudantes assumiram essa responsabilidade apenas em parte. Para eles, a Universidade é a maior responsável por promover mudanças positivas no processo educativo. Nesse sentido, mostrou-se representativo o seguinte depoimento: "Teria que ser um conjunto de tudo; precisamos de estrutura [física] boa, isso que é o papel da instituição; de um professor que saiba utilizar as coisas que a instituição oferece; de alunos interessados no que o professor passa" (A2).

Já no curso de Letras, por unanimidade, os estudantes se apresentaram como os maiores responsáveis pelo sucesso ou insucesso do processo educacional, como representam as declarações: “A instituição está aqui para passar o conteúdo; o professor, para ensinar; então, acho que a questão de interesse é do aluno" (A8); “O aluno não lê muito; estamos num curso de Letras, a gente vai ser professor, a gente vai pedir a leitura de um livro, a gente vai pedir a resolução de um exercício" (A9). 
Com essas constatações, pôde-se relacionar, ainda que provisoriamente, a presença da autocrítica com a da articulação dos diversos conteúdos. Isso porque entre os professores do primeiro curso prevalece a prática de manter a avalanche de informações sobre os estudantes, embora aqueles reconheçam oportunidades de melhorar a articulação dos aspectos informativos e formativos da educação. No segundo curso, esta articulação está mais presente.

Tal relação é provisória, como mencionado. Porém, considerável. Pode ser explicada em termos de "aluno que se espelha no professor". Na medida em que articula os conteúdos e deixa isto perceptível aos alunos, o professor efetivamente se inclui no processo educacional, não apenas repassando conceitos. Por sua vez, o aluno percebe tal dinâmica. Geram-se oportunidades de autocrítica. Ainda que haja a mútua culpabilização, esta é arrefecida porque, espelhando-se no professor, o aluno se inclui no processo educacional.

Já com relação aos professores, em vez de autocrítica, intensificou-se o discurso da culpa dos alunos pelo sucesso ou insucesso do processo educativo. O nível, o interesse pelo curso ou a condição sociocultural foram aspectos importantes nessa culpabilização. Apesar disso, quando provocados, alguns assumiram que suas condutas poderiam ser diferentes: "Ainda estou muito preso à questão do conteúdo" (P3). Houve até um participante que, mesmo sem ser provocado, manteve alunos e instituição à margem de qualquer culpabilização: "O bom aluno do noturno trabalha o dia inteiro, mora longe; as meninas saem de casa, muitas ainda têm que deixar o almoço, pensar na roupa para lavar" (P1). Continuou, informando que "não posso dizer que a instituição é tão vilã. Porque, senão, vai ser muito cômodo, para mim, colocar todo o peso nela" (P1). 


\section{As contribuições para a reprodução sociocultural}

A pesquisa identificou aspectos da mútua culpabilização, crítica silenciosa e primazia da informação que remetem diretamente à ação pedagógica que impõe e inculca determinadas significações, já convencionadas, por meio da seleção e exclusão. Evidenciou-se que, em geral, independentemente da fonte da culpabilização, os alunos são responsabilizados pelos insucessos do processo educacional quando as percepções sobre eles se relacionam com a interação social construída com seus professores ou entre eles. Assim, segundo percepções, são culpados porque não dialogam com seus professores e não assumem que é deles mesmos a maior responsabilidade pelas notas obtidas nas avaliações. Entretanto, não é só isso. São culpados porque chegam despreparados à educação superior; priorizam a aquisição do diploma; não leem; não se interessam pelo curso. Em outros termos, falta capital cultural àqueles que alcançam a educação superior de massa. Nesse sentido, foi significativa a declaração de uma professora: "A turma que vai fazer o Enade... Eles são moscas mortas. Eu tento chamar a atenção. Eles não se conectam comigo. Eu não consigo chegar até eles" (P5). Além disso, ainda de acordo com percepções, são culpados porque conversam muito durante as aulas, não se posicionam com ideias e opiniões e não possuem ideais relacionados à educação.

Por sua vez, a atribuição de culpa aos professores esteve relacionada, principalmente, com a percepção de que são indivíduos sem a prática regular de leitura e sem reflexão acerca dos seus modos de ensinar e avaliar o efetivo aprendizado pelos alunos. Por fim, a universidade é considerada culpada quando é percebida como instituição que não contribui para ampliar a compreensão dos alunos sobre o papel do pedagogo, não arca com pequenos custos do processo educacional (cópias, certificados), pouco contribui para que os alunos efetivamente encontrem sentido no curso, não escuta suficientemente alunos e professores, organiza turmas numerosas, não analisa e reavalia permanentemente os modos de acompanhar a efetividade do aprendizado.

Essas percepções constituem aspectos da ação pedagógica que seleciona e exclui na medida em que são abandonados princípios mais ou menos universais, como a capacidade humana de promover o diálogo, o que abriria possibilidades de mudanças no 
processo educacional. Desse modo, são percepções que levam à mútua culpabilização e, na sequência, à inércia de estudantes, professores e universidade.

Com relação à crítica silenciosa, identificaram-se certas limitações à manifestação sobre o processo educacional pelos estudantes. Estes não criticam abertamente a atuação dos professores porque entendem haver uma hierarquia entre eles, difícil de ser quebrada, por entenderem a crítica como ato de grosseria, pelo receio de prejudicarem os professores (podem perder turmas) e medo de serem considerados persona non grata pelos colegas. Outros ainda não se interessam em oferecer críticas. Às vezes, reclamam dos modos de ensinar, porém, não conseguem expor suas opiniões porque a turma é numerosa. Eles permutam ideias em rodas na turma, sem as evidenciarem, pois não creem que manifestar críticas promova mudanças. Trocam opiniões no intervalo, nos corredores e nas redes sociais, sem as tornarem públicas. Às vezes, como dito, "há uns [professores] que são mais abertos, né, pra gente falar quando está explicando. E tem outras [professoras] que não, que acham que a gente tá falando só pra criticar mesmo. Aí já fica nervosa e grita com a sala inteira" (A2).

Essas limitações impedem de colocar as críticas à vista. Nesse impedimento há seleção de significações. Desaparecem quaisquer reconhecimentos da capacidade crítica dos alunos. Nesse contexto, possivelmente os membros da escola pouco perceberão os elos que vinculam suas ações à configuração social em que estão inseridos. Dessa maneira, o não reconhecimento da capacidade crítica, acompanhado das consequências que levam à negação parcial dos sujeitos, faz com que os implicados não percebam que a escola, em função de sua força institucional, produz e reproduz as condições que a tornam reprodutora de determinada cultura. A negação parcial dos sujeitos garante o desejo de neutralidade da escola, solidificando a reprodução sociocultural e contribuindo para camuflar o rosto da ação pedagógica que se submete ao sistema de ensino dominante.

Já a primazia da informação foi identificada nos momentos em que os professores não escutam o aluno, se valem de informações para impor procedimentos ou quando desconsideram a capacidade de o aluno visualizar a finalidade dos conhecimentos adquiridos. Alunos percebem alguns professores com certa dificuldade de desenvolver os conteúdos ou, quando o conseguem, não verificam se os alunos efetivamente 
aprenderam. Percebem ainda que parte dos professores os superlotam com informações, às vezes, desnecessárias: “Eu vejo que muitos conteúdos (...) que eu aprendo aqui no curso de Pedagogia, eu não vou utilizar pra nada! Tem muita coisa ali que não tem utilização na prática" (A5). Como não percebe ou falta mesmo significado, reage com o desinteresse.

Esses momentos do processo educacional favorecem o estabelecimento da reprodução sociocultural. Se não tendentes para o autoritarismo, a maioria deles se projeta neste sentido, pois significações são transmitidas aos estudantes como legítimas, sem discussão crítica, caracterizando uma violência simbólica que ressalta as relações de poder.

\section{Os processos de transferência da reprodução sociocultural}

Após identificar nos processos educacionais pesquisados as lógicas da mútua culpabilização, da crítica silenciosa e da primazia da informação, e suas contribuições para a reprodução sociocultural, buscou-se descobrir como ocorre a possível transferência dessas lógicas da sala de aula da universidade para a da escola da educação básica. Nesse sentido, o cruzamento das respostas obtidas a partir de quatro perguntas que centralizaram a geração de dados levou a identificar aberturas para essa passagem e apontar oportunidades na atuação docente capazes de promover rupturas.

A seguir, apresentam-se resultados e análises obtidos com as quatro perguntas: $O$ que você imitará de seu professor? O que não imitará? O que gostaria que seus alunos imitassem de sua atuação? O que não gostaria que imitassem? 
Quadro 4-O que o aluno imitará ou não dos seus professores.

\begin{tabular}{|c|c|c|}
\hline$P$ & O que o aluno imitará & O que o aluno não imitará \\
\hline $\mathrm{A} 1$ & $\begin{array}{l}\text { Prática de evidenciar a lógica de } \\
\text { determinados assuntos para } \\
\text { desmistificar a percepção imediata de } \\
\text { que eles são complexos, facilitando o } \\
\text { ensino. }\end{array}$ & $\begin{array}{l}\text { Distanciamento entre teoria e prática } \\
\text { porque há desperdício de esforços na } \\
\text { medida em que a teoria vai para um } \\
\text { lado e a prática vai para outro. }\end{array}$ \\
\hline $\mathrm{A} 2$ & $\begin{array}{l}\text { Aulas dinâmicas, práticas, em que os } \\
\text { alunos se percebam donos do trabalho } \\
\text { realizado na sala de aula porque isso } \\
\text { traz satisfação pessoal. }\end{array}$ & $\begin{array}{l}\text { Prática da aula expositiva, só leitura e } \\
\text { revisões de textos porque isso é } \\
\text { cansativo. }\end{array}$ \\
\hline A3 & $\begin{array}{l}\text { Vontade e alegria de ministrar aulas, } \\
\text { percebidas em uma professora, } \\
\text { porque isso se traduz em benefícios ao } \\
\text { aprendizado dos alunos. }\end{array}$ & $\begin{array}{l}\text { Distanciamento } \\
\text { afetivo, } \\
\text { individualizado, entre alunos e } \\
\text { professores porque isso impede } \\
\text { averiguar a efetividade do } \\
\text { aprendizado. }\end{array}$ \\
\hline A4 & $\begin{array}{l}\text { Prática de deixar os alunos à vontade } \\
\text { para expressar ideias porque isso } \\
\text { dinamiza a aula, tirando a figura do } \\
\text { professor do centro do processo } \\
\text { educacional. }\end{array}$ & $\begin{array}{l}\text { Quaisquer atitudes de arrogância do } \\
\text { professor. }\end{array}$ \\
\hline A5 & $\begin{array}{l}\text { Prática de evidenciar a lógica de } \\
\text { determinados assuntos para } \\
\text { desmistificar a percepção imediata de } \\
\text { que eles são complexos, facilitando o } \\
\text { ensino. }\end{array}$ & $\begin{array}{l}\text { Ausência de planejamento relacionada } \\
\text { ao domínio de conteúdos e das } \\
\text { práticas docentes porque isso leva os } \\
\text { alunos à falta de participação e } \\
\text { aprendizado com a prática docente. }\end{array}$ \\
\hline A6 & $\begin{array}{l}\text { Abertura oferecida por professores } \\
\text { aos alunos para a participação porque } \\
\text { isso os deixa satisfeitos. }\end{array}$ & $\begin{array}{l}\text { Descumprimento do planejado, pois } \\
\text { isso leva o aluno a perder-se um } \\
\text { pouco, inclusive, com relação às } \\
\text { leituras. }\end{array}$ \\
\hline A8 & $\begin{array}{l}\text { Incentivo, dedicação, abertura para } \\
\text { que o aluno se apresente e se } \\
\text { expresse na frente da sala de aula; } \\
\text { importar-se com a vida pessoal do } \\
\text { aluno; debater; formar círculos de } \\
\text { estudo na sala de aula. }\end{array}$ & $\begin{array}{l}\text { Ausência de planejamento relacionado } \\
\text { ao domínio de conteúdos, pois não } \\
\text { deseja ser percebido como pessoa } \\
\text { despreparada na sala de aula. }\end{array}$ \\
\hline A10 & $\begin{array}{l}\text { Descontração de professores; } \\
\text { explicação clara dos assuntos e } \\
\text { organização, de modo a ser um } \\
\text { professor que equilibra seriedade e } \\
\text { descontração com o objetivo de } \\
\text { chamar atenção dos alunos para si. }\end{array}$ & $\begin{array}{l}\text { Práticas de professores malquistos } \\
\text { pelos alunos porque isso causa } \\
\text { sofrimento ao professor. }\end{array}$ \\
\hline
\end{tabular}

Fonte: elaboração dos autores. Legenda - P: Participantes. Obs.: somente os que se pronunciaram. 
Quadro 5 - Em que o professor gostaria ou não que os seus alunos o imitassem.

\begin{tabular}{|c|c|c|}
\hline$P$ & $\begin{array}{l}\text { O que o professor gostaria que o } \\
\text { aluno imitasse dele }\end{array}$ & $\begin{array}{l}\text { O que o professor gostaria que o } \\
\text { aluno não imitasse dele }\end{array}$ \\
\hline $\mathrm{P} 2$ & $\begin{array}{l}\text { Demonstração de emoções na sala de } \\
\text { aula. }\end{array}$ & $\begin{array}{l}\text { Conduta de não se dedicar na medida } \\
\text { suficiente aos estudos, ao } \\
\text { conhecimento dos conteúdos, à } \\
\text { pesquisa; o hábito de não ouvir os } \\
\text { alunos em sugestões para mudar os } \\
\text { métodos de ensino; o hábito de não } \\
\text { concluir alguns raciocínios, portanto, } \\
\text { não "concluir e dar início a outro" } \\
\text { assunto. }\end{array}$ \\
\hline $\mathrm{P}_{3}$ & $\begin{array}{l}\text { Percepção da apatia de alunos com } \\
\text { relação aos conteúdos desenvolvidos } \\
\text { e em seguida refletir com eles sobre } \\
\text { tal apatia porque isso promove } \\
\text { mudança de percepções, atitudes e } \\
\text { comportamentos. }\end{array}$ & $\begin{array}{l}\text { Conduta inflexível adotada, às vezes, } \\
\text { como, por exemplo, fazer chamada } \\
\text { nas aulas - a burocracia invade a } \\
\text { atuação docente, desde a formação } \\
\text { inicial até a atuação dos futuros } \\
\text { professores. }\end{array}$ \\
\hline $\mathrm{P} 4$ & $\begin{array}{l}\text { Incentivo à leitura na sala de aula: } \\
\text { "Que não substitua o texto pela } \\
\text { conversa a respeito do texto!". }\end{array}$ & $\begin{array}{l}\text { Prática excessiva de aulas expositivas } \\
\text { porque, com isso, os alunos não } \\
\text { refletem sobre os assuntos em } \\
\text { exposição: “Eu sei por prática que a } \\
\text { aula expositiva é uma aula que rende } \\
\text { pouquíssimo... Esse blábláblá”. }\end{array}$ \\
\hline $\mathrm{P}_{5}$ & $\begin{array}{l}\text { Prática de não excluir alunos } \\
\text { desabituados de falar a norma culta: } \\
\text { "Vocês não têm o direito de negar } \\
\text { isso pro seu aluno porque, ao fazer } \\
\text { isso, vocês o excluem". }\end{array}$ & $\begin{array}{l}\text { Impaciência com alunos } \\
\text { desinteressados porque isso segrega, } \\
\text { exclui: "Gostaria muito que os alunos } \\
\text { estudassem mais por conta própria e } \\
\text { a minha atitude quando eu percebo } \\
\text { que o aluno não quer nada com nada, } \\
\text { às vezes, segrega". }\end{array}$ \\
\hline P6 & $\begin{array}{l}\text { Concepção de que o professor é } \\
\text { incompleto para dar aula porque ele } \\
\text { lida com o ser humano: "O professor } \\
\text { num tá lidando com máquina". }\end{array}$ & $\begin{array}{l}\text { Modo de chamar atenção de alunos } \\
\text { que provocam dispersão na sala de } \\
\text { aula. Faz isso, sendo brincalhão, } \\
\text { porém, gostaria de fazê-lo de maneira } \\
\text { mais incisiva, direta, até para ensinar } \\
\text { aos futuros professores. }\end{array}$ \\
\hline
\end{tabular}

Fonte: elaboração dos autores. Legenda - P: Participantes. Obs.: somente os que se pronunciaram. 
Como se pode constatar pelos Quadros 4 e 5 , quaisquer respostas às quatro perguntas haveriam de situar-se no âmbito da ação docente. No Quadro 4 apresentam-se práticas e condutas indesejadas pelos estudantes que participaram da pesquisa. Assim, verificaram-se atitudes e comportamentos docentes que parecem contribuir para a percepção cultuada de que eles, professores, não estariam a ler o quanto deveriam. Há a percepção de que eles não refletem na medida necessária sobre seus modos de ensinar, suas concepções, especialmente a respeito do mundo e do ser humano e assim verificar o efetivo aprendizado pelos alunos. De fato, o professor precisa ser estudioso dos mais complexos problemas modernos, da civilização, da sociedade e do ser humano (TEIXEIRA, 1978).

A despeito do que deve assumir o professor em seu papel perante os alunos, essas condutas e percepções se convertem em filões por onde palmilham os processos de reprodução da reprodução sociocultural na medida em que alimenta o círculo vicioso da mútua culpabilização. Nesse círculo, de acordo com a pesquisa, o aluno é percebido, entre outros atributos, como pouco afeito à leitura, pouco disposto a dialogar com os professores sobre os processos educacionais e sem o hábito de posicionar-se diante de questões educacionais. Um círculo que alcança até a percepção de que a universidade não escuta efetivamente alunos e professores. Alcança também a percepção de que a universidade não perscruta a compreensão dos alunos sobre o papel do pedagogo. Num e noutro caso - escutar ou perscrutar o aluno - é razoável admitir que o rompimento de tal círculo vicioso exija, prioritariamente, modos de agir e se comportar do professor, na interação com seus alunos, capazes de romper os fios da separação, do distanciamento, da fragmentação e do monólogo, bases da reprodução sociocultural.

As condutas e percepções identificadas pela pesquisa constroem outros dutos por onde passa a reprodução sociocultural, indo da formação inicial dos professores à sua atuação na educação básica. Forja-se outro círculo vicioso, o da crítica silenciosa, pela qual ficam na sombra as opiniões, as discussões e as críticas sobre o processo educacional. É mesmo o caso quando o professor não lê e não pesquisa, pois isto interfere na troca de ideias e no desejo da quebra salutar de hierarquias durante as discussões com seus alunos. São condutas e percepções que podem se espalhar pela instituição, fortalecendo condições que a tornam cada vez mais reprodutora de culturas. 
O último círculo vicioso, o da priorização de aspectos informativos da educação e não a sua articulação com os formativos, alimenta-se de algumas das condutas apresentadas. Assim, por exemplo, o uso excessivo da exposição e o pouco hábito de o professor realizar pesquisas interferem na percepção dos alunos sobre a inutilidade das informações e conhecimentos desenvolvidos na sala de aula. Parte dos alunos percebe que os professores se valem de informações para impor procedimentos que poderiam ser discutidos. Os problemas da arrogância, os planejamentos mal elaborados ou não executados, o distanciamento afetivo, a antipatia e a impaciência se constituem em aberturas ao prosseguimento da reprodução sociocultural, pois, sem o retorno dos alunos, o professor passa a sentir-se à vontade para coagir e fica como cego diante do papel de contribuir para o desenvolvimento integral de seres humanos.

De todo modo, denotou-se que os alunos reagem ao conservantismo educacional (BEEBY, 1979) e, ao menos no discurso, afirmaram que não atuarão como seus professores. A contradição da mudança, na tensão dialética, já emerge. Há no discurso o germe da mudança - obviamente, nas condições práticas da escola básica, no seu dia a dia, a reação poderá ser outra. Por isso, com base nos resultados da pesquisa, buscou-se apresentar áreas da educação formal que na correria do dia a dia terminam por ficar na penumbra. É semelhante à dor na mão machucada, percebida apenas quando com ela se mexe. Nas filigranas do cotidiano podem esconder-se aspectos da prática docente capazes de sugar os envolvidos nela para o vácuo da reprodução sociocultural. E assim flutuam dissimulados, contudo, eficazes ao que vieram.

Noutra perspectiva, conforme o Quadro 5, existem práticas e condutas docentes cujo desejo dos participantes é a sua permanência, pois pretendem reproduzi-las. Referem-se prioritariamente a atitudes e comportamentos que promovem movimento contrário à reprodução sociocultural. Podem contribuir, e apenas isto, contribuir, com a ação docente comprometida com a transformação social. Com efeito, ao descontruírem a leitura fatalista da teoria da reprodução, Bourdieu e Passeron (1992) já tiravam a responsabilidade de transformação exclusivamente sobre os ombros de professores, alunos, famílias, governos, sindicatos, haja vista estarem integrados num sistema de relações que os legitimam e os afirmam individualmente. Não está na ação isolada do professor a solução em torno da educação que só reproduz. Os problemas do dia a dia da 
escola são mais amplos do que aparentam à primeira vista, envolvendo aspectos históricos, políticos e sociais e, dificilmente são superados em si mesmos ou apenas pela ação do professor.

Essa educação, articulada com o mundo e, assim, exigente da prática educativocrítica encontra na lição freireana a convicção de que o ato educativo é maneira de intervir no mundo. A educação não foi, é, ou será neutra. Por isso, tal intervenção ultrapassa o mero conhecimento de conteúdos, e sim "implica tanto o esforço de reprodução da ideologia dominante quanto o seu desmascaramento [grifos do autor referenciado]" (FREIRE, 2009, p. 98). Decorre, então, que o professor precisa definir-se politicamente.

Por isso, a autocrítica é importante, contribuindo para promover a transformação sociocultural. Se praticada permanentemente por alunos e professores, possibilita a geração de círculo virtuoso capaz de, por exemplo, no caso da educação brasileira, eliminar paulatinamente o alegado traço cultural de transferir responsabilidade quando o indivíduo que a transfere percebe que algo inesperado ocorreu ou quando a culpa ou o problema principal se localiza fora da sua área de atuação e controle (PRATES; BARROS, 1997). A autocrítica contribui para que esse indivíduo se reconheça mais como ser de e para a crítica. Em se referindo a cursos de formação inicial de professores, o educador que exercita a auto-observação para, em seguida, promover e evidenciar a articulação entre aspectos informativos e formativos da educação e, simultaneamente, "avisar" aos alunos quais condutas devem ou não ser reproduzidas, estará conferindo sentido ao seu papel social de transformar o processo educacional e a sociedade. Desse modo, na autocrítica, esse educador aprende a lidar com as torrentes de informação do mundo atual, convertendo-as em sentidos, em sabedoria. 


\section{Considerações finais}

A lógica da mútua culpabilização conduz à tendência de inércia do sistema e, assim, se abrem os flancos para a manutenção da reprodução sociocultural. Essa lógica será menos utilizada quanto mais o educador estiver comprometido com o desenvolvimento integral do educando. O educador que confere importância a essa atitude se situa próximo dos educandos, conciliando o que diz com o que faz. Reconhecese ignorante, embora busque aprender. Não é autoritário. Atenta para a avaliação de si feita pelos educandos. Posiciona-se politicamente (FREIRE, 2009). Por sua vez, a lógica da crítica silenciosa é artefato preferencial para a negação parcial dos sujeitos. É possível debelá-la, no mínimo como condição necessária, se o educador dialoga com o educando e com o mundo, o que gera abertura, impulsionando a capacidade crítica, bem como a curiosidade e a criatividade. Com essas atitudes e comportamentos, esse educador contribui para a elaboração e reelaboração de conhecimentos. Enfim, a lógica da primazia da informação sustenta o autoritarismo na medida em que, frequentemente, favorece a imposição de ideias, opiniões, valores sem refletir as intenções do grupo humano envolvido. Para conter o uso de tal lógica, o educador prioriza os processos de humanização, desmontando a primazia da informação. Estabelece numa só perspectiva formativa a ecologia dos saberes, a educação para valores e o equilíbrio entre emoção e razão.

Confirmam-se neste trabalho conclusões anteriores sobre a prática didáticopedagógica necessária à transformação social, ao contrário da reprodução pela mera reprodução. Reitera-se que, entre os participantes, ponderados os impactos das demais experiências sociais ao longo da vida, há potenciais que podem ser efetivas correntes de mudança, desde que os professores: 1) antes de atribuírem quaisquer culpas ao outro (estudante, universidade, governo), assumam-se como agentes promotores de mudanças; 2) admitam desde cedo que os estudantes são pessoas interessadas, tendo expectativas positivas quanto ao preparo para o mundo do trabalho e para serem cidadãos participativos; 3) mantenham-se abertos, sem dogmatismos, estimulando a curiosidade e o espírito crítico dos educandos; 4) reorganizem de modo contínuo a didática; 5) conduzam-se a partir do ideal de horizontalização das relações entre educandos e educadores; 6) mantenham-se atentos à necessária articulação entre 
saberes, valores e emoções, tripé da educação que forma para a integralidade humana. Essas são condutas, inclusive, fortemente engendradas a partir de estratégias capazes de "ativar" o sistema educacional.

Nesse sentido, pensar o sistema educacional ativo é admiti-lo bastante forte para acolher fragmentos do dia a dia, numa sociedade com interações pessoais cada vez mais pulverizadas. Implica, sobretudo, exercitar a capacidade de dialogar com os diferentes sentidos a que chegam os envolvidos na relação educacional. Portanto, é trazer o mundo para dentro desta relação, imprimindo no dia a dia dos membros da escola as atualizações de um tempo que muda vertiginosamente. Sobretudo, é mostrar às pessoas o sentido de suas ações. E o sentido virá simultaneamente à chegada dessas atualizações. É tudo junto.

No mundo conturbado em que se vive hoje, cabe refletir se já não é mesmo o tempo de a coruja de Minerva alçar voo, pelos menos entre os envolvidos e os interessados em promover uma educação melhor. Tanto já se estudou sobre os processos de reprodução sociocultural... É preciso agir. Nestes tempos com ares de crepúsculo, povos do mundo inteiro, milhões de vida, permanecem à espera de se cumprirem as promessas modernas de liberdade, igualdade e solidariedade (SANTOS, 2007). É preciso coragem. É preciso quebrar ovos e fazer omelete. Senão, ano após ano, persistirá o pelicano do capitão Jonathan a experimentar diuturnamente nova cor, embora, persistentemente, relute em manter sua essência (BOURDIEU; PASSERON, 1992). Parece claro ser necessário iniciar para já uma efetiva pedagogia da inclusão humana. 


\section{Referências}

BAUMAN, Zygmunt. Modernidade líquida. Rio de Janeiro: Jorge Zahar Editor, 2001.

BEEBY, C. E. Educação e desenvolvimento econômico. 3. ed. Rio de Janeiro: Zahar Editores, 1979.

BOUDON, Raymond; BOURRICAUD, François. Dicionário crítico de sociologia. São Paulo: 1993.

BOURDIEU, Pierre; PASSERON, Jean-Claude. Les héritiers: les étudiants et la culture. Paris: Éd. de Minuit, 1964.

BOURDIEU, Pierre; PASSERON, Jean-Claude. A reprodução: elementos para uma teoria do sistema de ensino. 3. ed. Rio de Janeiro: Livraria Francisco Alves Editora S. A., 1992.

BRASIL. Lei $\mathbf{n}^{\circ}$. 9.394, de 20 de dezembro de 1996. Brasília: Casa Civil, 1996. Disponível em: <http://www.planalto.gov.br/ccivil_03/Leis/L9394.htm>. Acesso em: 05 dez. 2015.

COLL, César, et al. Os conteúdos na reforma: ensino e aprendizagem de conceitos, procedimentos e atitude. Porto Alegre: Artes Médicas, 1998.

CUNHA, Maria Isabel da. O bom professor e sua prática. Campinas: Papirus, 1989.

DELORS, Jacques, et al. Educação um tesouro a descobrir: relatório para a UNESCO da Comissão Internacional sobre Educação para o século XXI. São Paulo: Cortez Editora; UNESCO no Brasil, 1998.

DUBET, François. Sociologia da experiência. Lisboa: Instituto Piaget, 1994.

DUBET, François. Qual democratização do ensino superior? Caderno CRH, Salvador, v. 28, n. 74, p. 255-265, 2015.

FREIRE, Paulo. Pedagogia da autonomia: saberes necessários à prática educativa. São Paulo: Paz e Terra, 2009.

FREIRE, Paulo. Pedagogia do oprimido. 50. ed. São Paulo: Paz e Terra, 2011.

PRATES, Marco Aurélio Spyer; BARROS, Betania Tanure de. O estilo brasileiro de administrar: sumário de um modelo de ação cultural brasileiro com base na gestão empresarial. In: MOTTA, Fernando C. Prestes; CALDAS, Miguel P. (Org.). Cultura organizacional e cultura brasileira. São Paulo: Atlas, 1997. p. 55-69.

ROUSSEAU, Jean-Jacques. Discurso sobre a origem e os fundamentos da desigualdade entre os homens. Os Pensadores. São Paulo: Editora Nova Cultural Ltda., [1755] 1997. 
SANTOS, Boaventura de Sousa. Pela mão de Alice: o social e o político na pósmodernidade. 10. ed. São Paulo: Cortez, 2005.

SANTOS, Boaventura de Sousa. Renovar a teoria crítica e reinventar a emancipação social. São Paulo: Boitempo, 2007.

SAVIANI, Dermeval. Escola e democracia: teorias da educação, curvatura da vara, onze teses sobre a educação política. 40. ed. Campinas: Autores Associados, 2008.

SERRES, Michel. Polegarzinha. Rio de Janeiro: Bertrand Brasil, 2013.

TEIXEIRA, Anísio Spínola. Pequena introdução à filosofia da educação: a escola progressista ou a transformação da escola. 8. ed. São Paulo: Editora Nacional, 1978.

VASCONCELOS, Ivar César Oliveira de; GOMES, Candido Alberto da Costa. Jovens estudantes universitários e seus professores em interação social. Atos de pesquisa em educação, Blumenau, v. 10, n. 2, p. 605-629, 2015. Disponível em:

<http://proxy.furb.br/ojs/index.php/atosdepesquisa/article/view/4316>. Acesso em: 05 dez. 2015. 